\title{
Correction to: A Latent Profile Analysis of Bisexual Identity: Evidence of Within-Group Diversity
}

\author{
Andrew Young Choi ${ }^{1} \cdot$ Karen Nylund-Gibson $^{2} \cdot$ Tania Israel $^{1} \cdot$ Stephanie E. A. Mendez ${ }^{1}$
}

Published online: 26 June 2019

(c) Springer Science+Business Media, LLC, part of Springer Nature 2019

\section{Correction to: Archives of Sexual Behavior https://doi.org/10.1007/s10508-018-1325-1}

This article has been corrected with the following revisions for errors unaddressed in the copy editing process. All of the revisions herein were technical in nature and did not substantively change any aspect of the content of the article, including main arguments and findings. The first author appreciates the understanding of the readers.

1. In the first subheading under Measures, "Bisexual Identity Interview" should be "Bisexual Identity Inventory."

2. In the first sentence under Measures, "7-item" should be "7-point."

3. In the third to the last sentence of the last paragraph under the Auxiliary Variables subsection under Procedure, "other two profiles" should be "other profiles."

4. In the second sentence of the fourth paragraph under Results, the odds ratio of 2.06 should be 2.07 to reflect appropriate rounding to the hundredth decimal place.

5. Under the Ambivalent column in Table 4, three logit values should be modified to represent appropriate rounding to the hundredth decimal place.

a. In the first row, .31 should be .32 .

b. In the second row, -1.21 should be -1.22 .

c. In the fourth row, -.40 should be -.41 .

The original article can be found online at https://doi.org/10.1007/ s10508-018-1325-1.

Andrew Young Choi

achoi@ucsb.edu

1 Department of Counseling, Clinical, and School Psychology, University of California, Santa Barbara, Santa Barbara,

CA 93106, USA

2 Department of Education, University of California, Santa Barbara, Santa Barbara, CA, USA
6. In the last sentence of the third paragraph under Discussion, "they" should be "people in this profile."

7. In the second to the last sentence of the fifth paragraph under Limitations and Future Directions, "dimension bisexual identity" should be "dimension of bisexual identity."

The following references should be updated.

\section{References}

Israel, T., Lin, Y.-J., Goodman, J. A., Matsuno, E., Choi, A. Y., Kary, K. G., et al. (2016). Reducing LGBTQ stigma through online interventions. In H. M. Levitt \& B. L. Velez (Co-chairs), Psychotherapy and intervention research with $L G B T Q$ populations. Symposium conducted at the meeting of the American Psychological Association, Denver, CO.

Jang, Y., Park, N. S., Chiriboga, D. A., \& Kim, M. T. (2017). Latent profiles of acculturation and their implications for health: A study with Asian Americans in central Texas. Asian American Journal of Psychology, 8(3), 200-208. https://doi.org/10.1037/aap0000080.

Mohr, J. J., Jackson, S. D., \& Sheets, R. L. (2017). Sexual orientation selfpresentation among bisexual-identified women and men: Patterns and predictors. Archives of Sexual Behavior, 46(5), 1465-1479. https ://doi.org/10.1007/s10508-016-0808-1.

Publisher's Note Springer Nature remains neutral with regard to jurisdictional claims in published maps and institutional affiliations. 